\title{
Geopolítica e migrações no contexto de Utrecht: Colonos portugueses no Brasil meridional
}

\author{
José Damião Rodrigues \\ Universidade dos Açores / Centro de História de Além-Mar, Portugal \\ jdamiaorodrigues@gmail.com
}

Fecha de recepción: 14/02/2013

Fecha de aceptación:10/09/2013

\begin{abstract}
RESUMEN
En este trabajo abordaremos las negociaciones entre España y Portugal en torno a la Colonia de Sacramento y las consiguientes emigraciones portuguesas que tuvieron lugar hacia allí entre 1715 y 1750, fechas de los tratados de Utrecht y de Madrid. Finalizada la Guerra de Sucesión en España, Portugal recuperó la Nueva Colonia de Sacramento, consiguiendo que dicha colonia fuese reconocida por el rey Felipe $\mathrm{V}$ como el punto más meridional del dominio portugués en América, debido también a la presión británica ejercida por el embajador inglés en Utrecht y en Madrid, respectivamente. Con todo, la restitución de la plaza y el territorio de Sacramento en 1716 no significó el final de lo que serían unas dilatadas negociaciones entre las dos coronas ibéricas. Además, ante la necesidad de preservar su soberanía en estas regiones sur-brasileñas, la monarquía portuguesa promovió la ocupación estratégica de estos territorios, utilizando colonos provenientes de sus territorios europeos, en concreto de Trás-osMontes y de las islas Azores.
\end{abstract}

Palabras clave: Paz de Utrecht, Portugal, España, Sacramento, diplomacia, colonos, Azores.

\section{Geopolitics and migration in the context of Utrecht: Portuguese settlers in Southern Brazil}

\begin{abstract}
In this article, we will focus on the diplomatic negotiations between Spain and Portugal regarding the Colony of Sacramento and on the Portuguese migrations that took place from the Treaty of Utrecht (1715) to the Treaty of Madrid (1750). After the end of the War of the Spanish Succession, Portugal regained the New Colony of Sacramento, which was recognized as the most southern point in the Portuguese empire in the Americas. This was also due to the British pressure and the initiative of the English ambassador in Utrecht and in Madrid. However, the returning of the stronghold of Sacramento and its territory in 1716 did not put an end to a long negotiation between the two crowns. Besides, faced with the necessity of preserving its sovereignty in the regions of southern Brazil, the Portuguese monarchy promoted the strategic occupation of those territories by using settlers coming from its European domains, namely from Trás-os-Montes and from the Azores.
\end{abstract}

Key words: Peace of Utrecht, Portugal, Spain, Sacramento, diplomacy, settlers, Azores. 
1. Na segunda metade do século XVII, o avanço português em direcção à bacia do Rio da Prata, quer por iniciativa da coroa, quer pela acção de particulares, que procuravam jazidas e índios para capturar, traduziu-se no povoamento e colonização das regiões costeiras do Brasil meridional. No seguimento da criação de novos núcleos portugueses na costa do Brasil -São Francisco do Sul, Laguna, Nossa Senhora do Desterro-, a fundação da Nova Colónia do Sacramento, em 1680, na margem norte do Rio da Prata, assinalou uma inflexão na política portuguesa na região e, concomitantemente, representou uma etapa importante no processo de afirmação do Rio de Janeiro no contexto do império português ${ }^{1}$. Não apenas se comprovava a importância estratégica que a coroa portuguesa atribuía à bacia platina com a decisão de edificar uma posição fortificada, como se respondia positivamente aos interesses dos homens de negócio do Rio de Janeiro, desejosos de aceder ao trato com o Perú e ao gado que abundava na região, bem como ao trato de escravos que se desenvolvia na região do Rio da Prata ${ }^{2}$.

Os Castelhanos haviam atingido pela primeira vez a região em 1516, mas foi a segunda fundação de Buenos Aires, em 1580, que assinalou a afirmação definitiva das pretensões dos Áustrias à posse desse espaço. Compreende-se, pois, que a instalação de uma colónia portuguesa nas margens do Prata, cem anos mais tarde, em frente a Buenos Aires, representava uma ameaça real para os objectivos da Monarquia Católica. E de facto, cerca de 1700, a Nova Colónia do Sacramento afirmava-se já como "un serio rival de Buenos Aires en el comercio hacia el Alto Perú" . Abrira-se assim um foco de tensão acerca dos limites dos territórios ibéricos na América do Sul que marcou a política americana das monarquias portuguesa e espanhola entre os finais do século XVII e os começos do século XIX e que o Tratado de Utrecht não conseguiu resolver ${ }^{4}$.

Neste texto, pretendemos apresentar alguns elementos relativos às negociações hispano-portuguesas envolvendo a praça e o território da Colónia do Sacramento e à política que, no período posterior a 1715, a coroa portuguesa procurou implementar para garantir a ocupação e defesa dos territórios limítrofes do Brasil meridional, recorrendo a colonos oriundos da província de Trás-os-Montes e, sobretudo, das ilhas dos Açores.

1 Cf. Almeida, L. F.: A Diplomacia portuguesa e os limites meridionais do Brasil, vol. 2, Coimbra, Faculdade de Letras da Universidade de Coimbra, 1957; Almeida, L. F.: A Colónia do Sacramento na época da Sucessão de Espanha, Coimbra, Faculdade de Letras, 1973; SAMPAIO, A. C. J.: Na encruzilhada do império: hierarquias sociais e conjunturas econômicas no Rio de Janeiro (c. 1650-c. 1750), Rio de Janeiro, Arquivo Nacional, 2003, pp. 114 y 140-148.

2 Cf. Prado, F. P.: “Colônia do Sacramento: a situação na fronteira platina no século XVIII", Horizontes Antropológicos, 19 (2003), pp. 79-104.

3 Cf. Céspedes del Castillo, G.: América Hispana (1492-1898), Madrid, Fundación Jorge Juan-Marcial Pons Historia, 2009 p. 163.

4 Para uma síntese das relações entre Portugueses e Espanhóis ao longo das fronteiras na América do Sul neste período, ver Solano, F.: "Contactos hispanoportugueses en América a lo largo de la frontera brasileña (1500-1800)", Anexos de Revista de Indias, 4, Estudios (Nuevos e Viejos) sobre la Frontera, coordinados por Francisco de Solano e Salvador Bernabeu, Madrid, 1991, pp. 187-215; Marchena FernándeZ, J.: “"De Espanha nem bom vento nem bom casamento». La guerra como determinante de las difíciles relaciones entre las dos coronas ibéricas en la Península y en América. 1640-1808", Anais de História de Além-Mar, 10 (2009), pp. 29-111. 
2. Aclamado rei em cerimónia realizada no Terreiro do Paço, em Lisboa, a 1 de Janeiro de 1707, D. João V iniciou o seu reinado com Portugal envolvido na Guerra de Sucessão de Espanha quase desde o início do conflito ${ }^{5}$. E, apesar de John Lynch ter considerado que Portugal constituía "one of the most vulnerable flanks of Philip $\mathrm{V}$ ", de facto, devido às suas limitações e tal como sucedera durante a Guerra da Restauração (1641-1668), o reino português foi palco da investida de tropas inimigas. Entre 1704 e 1711, a guerra afectou vastas áreas do Alentejo e da Beira, embora em 1706 o marquês das Minas tenha entrado em Madrid. A partir de 1707, com diversas vitórias das forças apoiantes de Filipe $\mathrm{V}$, a recuperação da dinâmica bourbónica inicial tornou a posição portuguesa mais difícil nos planos político e militar. A situação revelou-se particularmente crítica em 1710, com o saque dos campos e dos arredores de Miranda do Douro, praça que caiu em poder de forças espanholas em Julho, enquanto a sul o marquês de Bay atingiu Badajoz e preparou a entrada no reino de Portugal sem que houvesse oposição ${ }^{7}$, e de novo em 1712, com o cerco a Campo Maior. Este cenário prolongava-se à América do Sul e às disputas hispano-lusas em torno da estratégica bacia do Rio da Prata e da Nova Colónia do Sacramento, um conflito que se reacendeu por diversas vezes durante o longo reinado de D. João V e que conduziu a diversas negociações entre as monarquias ibéricas, as quais culminaram, num primeiro momento, na assinatura do Tratado de Madrid ou dos Limites, a 13 de Janeiro de $1750^{8}$.

Nos anos finais da guerra, o estabelecimento da paz com Filipe $V$ revelou-se uma preocupação central de D. João V. Sobre esta matéria, é interessante conhecer a perspectiva espanhola, tal como nos foi transmitida pelo marquês de San Felipe. Nos comentários que teceu sobre o conflito, o marquês afirmou que, nos preliminares das negociações de paz com Espanha, em 1711-1712, o rei de Portugal não fora nomeado, mas tratara secretamente da paz com Filipe V e que, mais tarde, em 1714, quando D. João V soube que Filipe V dera ordem aos seus plenipotenciários em Utrecht para não aceitarem a paz com Portugal, ameaçou auxiliar os sublevados de Barcelona, recorrendo de igual modo aos seus aliados para que não o abandonassem em caso de acção ofensiva por parte de Espanha9.

A Guerra da Sucessão de Espanha terminou com a assinatura dos vários tratados bilaterais de Utrecht e de Rastatt (1713-1715), que redesenharam o mapa político europeu e estabeleceram as bases do novo equilíbrio imperial e da futura supremacia

5 Sobre esta conjuntura, Cardoso, J.L., Cluny, I., Dores Costa, F. y otros: O Tratado de Methuen (1703): diplomacia, guerra, política e economia, Lisboa, Livros Horizonte, 2003.

6 Cf. Lynch, J.: Bourbon Spain, 1700-1808, Oxford-Cambridge, Mass., Basil Blackwell, 1993 (edição original: 1989), p. 26.

7 Cf. Rodrigues, J. D.: “1710”, en Carneiro, R., Matos, A. T., Costa, J. P. O. (coords.): Portugal, Anos 10, Alfragide, Leya-Texto Editores, 2010, pp. 139-162 y 156-157.

8 Sobre o Tratado de Madrid, os seus antecedentes e as negociações, ver ConTESão, J.: Alexandre de Gusmão e o Tratado de Madrid, Brasília-São Paulo, FUNAG-Imprensa Oficial do Estado de São Paulo, 2006 (edição original: 1950-1963), 2 tomos; Almeida, L. F.: Alexandre de Gusmão, o Brasil e o Tratado de Madrid (1735-1750), Coimbra, INIC, Centro de História da Sociedade e da Cultura, Universidade de Coimbra, 1990; MARChENA, op. cit., (nota 4), pp. 56-66 para o reinado de D. João V.

9 Cf. Bacallar y Sanna, V., Marquês de San Felipe: Comentarios de la guerra de España e Historia de su rey Felipe V, el Animoso, edição e estudo preliminar de D. Carlos Seco Serrano, Madrid, Ediciones Atlas, 1957 , pp. 228-229 y 247. 
britânica ${ }^{10}$. Apesar de difícil e contestada, logo após a assinatura dos vários tratados bilaterais, a Paz de Utrecht foi baseada no consenso. Não obstante a política expansionista francesa e as tentações de algumas potências para cobrarem à França os custos dessa política, a diplomacia inglesa soube conduzir as negociações de forma a evitar criar desequilíbrios no interior do sistema europeu de Estados. Não é possível dar conta da densa teia de negociações diplomáticas que se foi construindo durante $o$ período dos Congressos de Utrecht e Rastatt, de Cambrai e dos que se lhes seguiram na década de 1720. Convirá, todavia, recordar que o que designaríamos por "política externa" das monarquias ibéricas dependia em parte dos respectivos alinhamentos diplomáticos no contexto da "sociedade dos príncipes" e, por conseguinte, da relação que Portugal tinha com a Grã-Bretanha e da que Espanha mantinha com a França, um quadro que perdurou ao longo de Setecentos ${ }^{11}$. Perante a demora na conclusão da paz, as mediações inglesa e francesa actuaram de modo a conseguir o desfecho das negociações ${ }^{12}$.

Assinado o Tratado de Paz entre D. João V e Filipe V a 6 de Fevereiro de $1715^{13}$, o rei de Portugal não hesitou em aproveitar a ocasião para, como em ocasiões anteriores, se afirmar em posição de paridade face ao rei de Espanha, o que foi observado pelo conde de Tarouca em carta enviada ao marquês de Angeja em moldes que parecem ecoar a posição do Conselho de Estado espanhol. Com efeito, o diplomata português destacou o facto de, contra o que era costume, "no Tratado original em português precedeu Elrey nosso senhor a Felipe 5. ${ }^{\circ}$ e eu ao duque de Ossuna (e vice versa)" ${ }^{14}$. Tratava-se de uma estratégia perseguida por D. João V face ao monarca espanhol e que continuaria nas décadas seguintes.

Finda a Guerra da Sucessão de Espanha, Portugal recuperou a Nova Colónia do Sacramento, abandonada em 1705, conseguindo que a colónia fosse reconhecida por Espanha como o ponto mais meridional do domínio português nas Américas devido também à pressão britânica e à acção do embaixador inglês Lord Lexington em Utrecht e em Madrid ${ }^{15}$. Recordamos que a descoberta de ouro no sertão paulista na última década de Seiscentos, "prometendo riquezas e felicidades ao reino de V. Magde.", nas palavras de D. João de Lencastre em carta a D. Pedro II, em 1701, confirmara a "ocidentalização" do império que se começara a desenhar no século XVII,

10 Cf. BÉly, L.: Les relations internationales en Europe (XVII ${ }^{-}$-XVIII ${ }^{e}$ siècles), Paris, PUF, 1992; OsIANDER, A.: The States System of Europe, 1640-1990. Peacemaking and the Conditions of International Stability, Oxford, Clarendon Press, 1994.

11 Sobre esta questão, numa perspectiva sobretudo espanhola, vejam-se os vários textos reunidos em Guimerá, A., Peralta, V. (coords.): El Equilibrio de los Imperios: de Utrecht a Trafalgar, Madrid, Fundación Española de Historia Moderna, 2005.

12 Cf. Brazão E.: Portugal no Congresso de Utrecht (1712-1715), Lisboa, s. n., Imprensa Lucas, 1933; Martín Marcos, D.: "La paz hispanoportuguesa de 1715: la diplomacia ibérica en Utrecht", Cuadernos de Historia Moderna, 37 (2012), pp. 151-175.

13 Cf. Castro, J. F. B.: Collecção dos Tratados, Convenções, Contratos e Actos Publicos celebrados entre a Coroa de Portugal e as mais Potencias desde 1640 até ao presente, compilados, coordenados e annotados por..., Lisboa, Imprensa Nacional, tomo II, 1856, pp. 262-272.

14 Cf. Cluny, I.: O Conde de Tarouca e a Diplomacia na Época Moderna, Lisboa, Livros Horizonte, 2006, p. 316.

15 Cf. LyNCH, op. cit., (nota 6), p. 36. 
e a importância do Brasil no contexto imperial português ${ }^{16}$. Ainda no começo da nova centúria, o realinhamento político da dinastia brigantina operado no contexto da Guerra da Sucessão de Espanha e materializado nos tratados celebrados em Março e Dezembro de 1703 consagrou a opção atlântica da monarquia portuguesa ${ }^{17}$.

Neste contexto, a defesa e consolidação da presença portuguesa na região sul-brasileira confirmava a importância geoestratégica que a coroa portuguesa atribuía à bacia platina e respondia positivamente aos interesses dos homens de negócio do Rio de Janeiro, desejosos de manter o trato com o Perú e de aceder ao gado que abundava na região. Ainda durante o decurso das negociações dos tratados que visavam estabelecer o fim da guerra, o experiente e bem informado D. Luís da Cunha, a partir de Utrecht, escrevera em meados de 1714 para a corte de Lisboa, comunicando que José da Cunha Brochado, em Londres, descobrira que existia um plano para o estabelecimento de uma colónia inglesa na América do Sul. E concluía que, acaso fosse na estratégica ilha de Santa Catarina ou na dos Patos, os proveitos resultantes da exploração e arrecadação do ouro ficariam em perigo, sendo urgente impedir que tal projecto fosse avante ${ }^{18}$. Se aquele projecto se gorou, os confrontos que envolveram as potências europeias ao longo do século XVIII e no início do século XIX demonstrariam que Franceses e Britânicos pretendiam, a todo o custo, garantir uma posição sólida no litoral entre os rios Amazonas e Prata. Assim, perante a necessidade de preservar a soberania portuguesa nas regiões sul-brasileiras, a coroa teve de equacionar o povoamento das regiões meridionais do Brasil e o Conselho Ultramarino cuidou de promover a ocupação do território com o recurso a casais oriundos de Trás-osMontes e dos Açores ${ }^{19}$. Esta era, de resto, uma prática que, desenhada no século XVI, se consolidou nas centúrias seguintes, definindo um "sistema de migração" ou "sistema migratório" patrocinado pela monarquia e que se destinava a garantir o povoamento das periferias imperiais ${ }^{20}$.

Logo em 1550, a própria coroa incentivou o provedor das armadas nos Açores, Pêro Anes do Canto, a recrutar açorianos que deveriam ser encaminhados para o

16 Cf. Souza, L. M. y Bicalho, M. F. B.: 1680-1720: o império deste mundo, São Paulo, Companhia das Letras, 2000, pp. 19 y 21.

17 Sobre o significado destes tratados, ver Cardoso, op. cit., (nota 5).

18 Cf. Furtado, J. F.: "Dom Luís da Cunha e a centralidade das minas auríferas brasileiras", Anais de História de Além-Mar, Lisboa, 8 (2007), pp. 69-88 y 79.

19 Cf. Monteiro, J. C. R.: A Colónia do Sacramento, 1680-1777, t. 2, Porto Alegre, Globo, 1937, p. 61; Magalhães, J. R.: "As novas fronteiras do Brasil", en Bethencourt, F., Chaudhuri, K. (dirs.): História da Expansão Portuguesa, vol. III: O Brasil na Balança do Império (1697-1808), Lisboa, Círculo de Leitores, 1998, pp. 10-42, maxime p. 10; SiLva, M. B. N.: D. João V, Lisboa, Círculo de Leitores-Centro de Estudos dos Povos e Culturas de Expressão Portuguesa, 2006, p. 210.

20 Cf. Hoerder, D.: Cultures in Contact: World Migrations in the Second Millennium, Durham-London, Duke University Press, 2002, p. 16: "A migration system, on the level of empirical observation of geographical space, is a cluster of moves between a region of origin and a receiving region that continues over a period of time and is distinct from nonclustered multidirectional migrations." Ao nível macroscópico, um sistema migratório une duas regiões ou sociedades distintas, com diferentes modelos políticos, graus de desenvolvimento social e económico, culturas e valores distintos e uma composição étnica também diversa. Estes sistemas são autoregulados na medida em que respondem, por assim dizer, às conjunturas políticas e económicas de acordo com a circulação de informação e os factores do nível meso articulam-se com os contextos individuais para a tomada de decisão dos actores sociais, que procuram, sempre que possível, avaliar os benefícios resultantes de uma dada escolha. 
Brasil, para apoio à fundação de São Salvador da Baía ${ }^{21}$. A coroa disponibilizava os meios de transporte e prometia terras como forma de aliciamento dos eventuais colonos. No século XVII, o modelo dos casais foi implementado na região amazónica após a expulsão dos Franceses de São Luís. O primeiro contingente de casais ilhéus chegou ao Maranhão em finais de 1618 e depois, ao longo de Seiscentos, várias levas de casais estão registadas, reforçadas no final da centúria com a presença de contingentes militares ${ }^{22}$. Mas a política de transporte de casais também se aplicou nas regiões meridionais do Brasil no seguimento da fundação da Nova Colónia do Sacramento. Durante os governos de D. Francisco Naper (1689-1699) e Sebastião da Veiga Cabral (1699-1705) foi manifesta a preocupação com o aumento populacional da Colónia. Este objectivo traduziu-se no pedido do envio de casais do reino ou das ilhas, diligência que mereceu a atenção do rei e do Conselho Ultramarino. Os conselheiros propuseram inicialmente que se remetessem casais da província do Entre-Douro-e-Minho, onde existiam "muitas pessoas e lavradores mizeraveis". Em 1694, D. Pedro II ordenou o envio de dez casais da Madeira e, em 1699, a ordem foi alargada de modo a contemplar o alistamento voluntário dos insulares. O deflagrar da Guerra da Sucessão de Espanha e as dificuldades que enfrentou a Colónia do Sacramento, conquistada em 1705 pelos Castelhanos, estancaram um fluxo que, até à data, se revelara débil ${ }^{23}$.

Mas a ideia de que as províncias e os territórios com maior densidade demográfica deviam concorrer para o povoamento das fronteiras do império não esmoreceu. Durante o período do conflito e antes ainda dos ataques franceses ao Rio de Janeiro, por ordens régias de 8 de Abril e 26 de Setembro de 1708, foi determinada a recruta na ilha Terceira e nas "ilhas de baixo" dos Açores de 200 homens destinados à capitania do Rio de Janeiro e de 120 ao Maranhão ${ }^{24}$. António do Couto de Castelo Branco (1669-1742), inspector régio enviado em 1709 às ilhas dos actuais grupos central e ocidental com a missão de inspeccionar o estado das fortificações e das guarnições pagas, bem como o das milícias, defendeu então a possibilidade de se retirarem casais das ilhas Graciosa, "porque a gente que ha é muita, e pouco o em que se occupem e

21 "Carta de elrei de 11 de Setembro de 1550 - Fundação da cidade da Bahia e colonos das ilhas", in Arquivo dos Açores, edição fac-similada da edição original, Ponta Delgada, Universidade dos Açores, vol. 12, 1983, pp. 414-415. Embora com motivações individuais, ligadas ao serviço do rei ou de Deus, os açorianos surgem, ainda no século XVI, nas principais frentes da expansão portuguesa, em África e na Índia. A este propósito, ver RodriguEs, J. D.: “Os Açores e a Expansão: bens e gentes no espaço colonial português (séculos XV-XVIII)”, Insulana, Ponta Delgada, 49 (1993), pp. 147-181.

22 Para uma exposição mais desenvolvida deste fluxo migratório, ver RodRigues, J. D. y MADEIRA, A. B.: "Rivalidades imperiais e emigração: os açorianos no Maranhão e no Pará nos séculos XVII e XVIII", Anais de História de Além-Mar, Lisboa, 4 (2003), pp. 247-263.

23 Cf. Almeida, L. F.: “Casais e lavradores na Colónia do Sacramento (1680-1705)", Revista Portuguesa de História, Coimbra, tomo XXX (1995), pp. 9-36.

24 Carta régia de 26 de Setembro de 1708, Biblioteca Pública e Arquivo Regional de Angra do Heroísmo (BPARAH), Arquivo da Câmara de Angra do Heroísmo (ACAH), Livro do Tombo [Registo] (1680-1726), fl. 100; vereação de 5 de Novembro de 1708, BPARAH, ACAH, Acórdãos, Livro 16 (1706-1714), fl. 113; Drummond, F. F.: Anais da Ilha Terceira, reimpressão fac-similada da edição de 1850-1864, vol. 2, Angra do Heroísmo, Secretaria Regional de Educação e Cultura, 1981, p. 229. 
com que vivam", e do Pico, "por ter mais gente da com que pode." 25 . Ou seja, face à pobreza das ilhas e à sua alegada sobrepopulação, a emigração constituiria uma resposta adequada, sobretudo quando se configurava como um serviço da monarquia, permitindo aumentar o número de brancos, nomeadamente de mulheres, na América.

A restituição da praça do Sacramento e do seu território, acordada no Tratado de Paz e concretizada em Novembro de $1716^{26}$, não significou o fim de arrastadas negociações, que estavam já em desenvolvimento nos finais desse ano, no tocante a compensações e à participação inglesa nas mesmas negociações ${ }^{27}$. Continuavam em aberto questões que tinham a sua origem nos anos iniciais do conflito e, no terreno, as demarcações revelaram-se de difícil execução, conforme atesta a correspondência trocada entre o governo da Colónia e a corte nos anos de 1718 e $1719^{28}$. Um dos problemas que se colocavam à tarefa de demarcar o território resultava da ausência de mapas da região por parte de Portugal, questão que mereceu a atenção de um dos diplomatas lusos presentes em Utrecht, D. Luís da Cunha. Homem culto e protótipo do diplomata cosmopolita e ilustrado da primeira metade de Setecentos, convicto de que Portugal carecia de bons mapas dos territórios onde existia um povoamento português e para os quais defendia uma maior ocupação do espaço, para defesa e conservação das conquistas de acordo com o princípio do uti possidetis, reclamou desde 1719 contra essa lacuna, advogando o uso da cartografia nas negociações diplomáticas ${ }^{29}$.

A falta de documentação cartográfica de qualidade tornar-se-ia mais evidente no início da década seguinte. A 27 de Novembro de 1720, em Paris, o Primeiro Geógrafo do Rei, Guillaume Delisle, leu perante a Academia das Ciências uma memória na qual expôs as suas reflexões sobre a questão da longitude. Os argumentos expostos tinham consequências para o estabelecimento dos meridianos de demarcação entre os territórios reivindicados por Portugal, e que o Tratado de Utrecht lhe reconhecera, e os das monarquias francesa e espanhola na América do Sul. De acordo com os cálculos de Delisle, as terras do Cabo do Norte e a colónia do Sacramento ficavam para além do Meridiano de Tordesilhas. D. Luís da Cunha, em Paris, adivinhou o aproximar da turbulência e, em 1721, comunicaria à coroa portuguesa o teor da dissertação de Delisle.

Outro dos problemas por resolver dizia respeito ao valor equivalente proposto por Filipe V pela Colónia do Sacramento em virtude do que ficara acordado na paz ajus-

25 Vereações de 19 de Fevereiro e 8 de Abril de 1710, respectivamente, BPARAH, ACAH, Acórdãos, Livro 16 (1706-1714), fls. 180 y 186; "Carta a El Rey nosso Senhor em que lhe faz relação Antonio do Couto das seis ilhas baixas e da Terceira, anno de 1709”, Arquivo dos Açores, vol. 12, 1983, pp. 460-472, 468 y 470.

26 Despacho de 29 de Julho de 1717, contendo carta do Pardo, de 23 de Julho de 1717, Archivo Histórico Nacional (AHN), Madrid, Estado, leg. 1773, n. 5 [s. no.], informando da recepção de outra do marquês de Capecelatro sobre ter-se recebido em Lisboa a notícia da posse da Colónia do Sacramento, devolvida aos Portugueses em Novembro de 1716, com um capítulo de carta escrita na Baía, de 15 de Abril de 1717.

27 Ibidem, leg. 1768, n. ${ }^{\circ}$ 39, de Madrid, 31 de Dezembro de 1716, sobre o equivalente proposto pela Colónia do Sacramento e a participação inglesa nas negociações, e n. ${ }^{\circ} 41$, de Madrid, 31 de Dezembro de 1716, também sobre o equivalente proposto pela Colónia do Sacramento.

28 SiLVA, op. cit., (nota 19), pp. 210-211.

29 Sobre esta questão, ver FuRTADO, op. cit., (nota 18), e, da mesma autora, "Guerra, diplomacia e mapas: a Guerra da Sucessão Espanhola, o Tratado de Utrecht e a América portuguesa na cartografia de D'Anville”, Topoi, Rio de Janeiro, vol. 12, 23 (Julho-Dezembro 2011), pp. 66-83. 
tada com Portugal em Utrecht, mais precisamente no Artigo 7. ${ }^{30}$. Para o Consejo de Indias, existiam grandes inconvenientes em entregar-se a Colónia a Portugal. Muita da actividade diplomática desenvolvida pelo embaixador espanhol na corte de Lisboa nos anos de 1716 e 1717 passou pela tentativa de evitar a devolução daquele território, para mais sabendo a corte espanhola da existência do projecto português de enviar casais para a América do Sul, tendo sido chamado à corte em Lisboa o cosmógrafo-mor, Manuel Pimentel, para informar onde poderia situar-se a nova colónia e tratar da respectiva demarcação ${ }^{31}$.

A diplomacia espanhola continuava a argumentar que a Colónia do Sacramento estava longe dos núcleos portugueses e que o seu solo não era fértil, por ser arenoso, constituindo apenas motivo de inquietação e gasto para o rei de Portugal, sabendo-se que, na corte portuguesa, tivera lugar uma Junta "con motiuo de disponerse algunas familias para ir a poblar la Colonia del Sacramento". O embaixador de Espanha na corte de Lisboa, o marquês de Capecelatro, informara que, segundo as demarcações feitas, supunha que a dita colónia pertencia a Espanha "y que Seria a su parecer mas conveniente se formase otra nueva en el territorio de Portugal, para Resguardar su propria JurisdiCión, que ponerse a nueuas Contingencias". Como estas propostas foram recusadas por D. João $\mathrm{V}$, o marquês teve uma conferência com o confessor do rei, que nada adiantou, falando depois sucessivamente com o Secretário de Estado, o cardeal da Cunha, o marquês de Minas e, de novo, o confessor régio. Todavia, conforme informava para a corte bourbónica o embaixador, os ministros portugueses "se demuestran misteriosos" 32 . Paralelamente, continuavam as conversações acerca da satisfação pedida pelos Portugueses relativa aos 600.000 pesos que pretendia o rei de Portugal em virtude do que ficara acordado no Capítulo 15 da paz ajustada entre ambas as coroas -o embaixador de Portugal na corte espanhola pedia 400.000 "escudos" devidos de dois anos passados e havia ainda a questão dos navios apresados no Rio de Janeiro, quase um ano antes da declaração de guerra ${ }^{33}$ - e sobre a restituição que devia ser feita dos navios espanhóis apresados no Rio de Janeiro e no Algarve ${ }^{34}$.

30 Com despacho de 18 de Janeiro de 1717, AHN, Estado, leg. 1773, n. ${ }^{\circ} 5$.

31 Ibidem, leg. 1791, n. ${ }^{\circ} 11$, de Madrid, 8 de Agosto de 1716, com duas consultas do Conselho das Índias sobre os graves inconvenientes de se entregar a Colónia do Sacramento a Portugal; n. ${ }^{\circ}$ 23, de Madrid, 6 de Outubro de 1716, com duas cartas do marquês de Capecelatro dando conta dos passos dados acerca do negócio do equivalente oferecido aos Portugueses pela Colónia do Sacramento, informando que por meio de ministro algum poderia saber qual era o ânimo do rei de Portugal sobre esse assunto e que tentara fazer passar a mensagem por via de um padre de São Filipe Neri, "en consideracion de la estrecha union y amistad que este professa con el Padre Confesor" de D. João V, referindo-lhe a distância a que ficava a Colónia do Sacramento de territórios portugueses, a sua proximidade com Buenos Aires e a conveniência de ambas as coroas, para que o comunicasse ao padre confessor, o que este não fez; n. ${ }^{\circ}$ 50, de Madrid, 22 de Dezembro de 1716, com duas consultas e cartas do marquês de Capecelatro dando conta dos passos dados acerca do negócio do equivalente oferecido aos Portugueses pela Colónia do Sacramento; n. ${ }^{\circ}$ 53, do Retiro, 28 de Agosto e 1 de Setembro de 1716.

32 Ibidem, leg. 1773, n. ${ }^{\circ} 5$ [s. n. ${ }^{\circ}$ ], com despacho de 28 de Janeiro de 1717.

33 Ibidem, n. ${ }^{\circ}$ 5, com despacho de 18 de Janeiro de 1715. Os 600.000 "escudos" [sic] eram devidos do comércio de negros e seriam pagos em três pagamentos iguais nas três primeiras frotas, flotilhas ou galeões.

34 Ibidem, n. 5 [s. n. ${ }^{\circ}$, com despacho de 12 de Março de 1717. Cf. ainda "Papeles y consultas sobre los 300.000 pesos que piden los portugueses", Biblioteca Nacional de España (BNE), Madrid, Ms. 3012. Inclui 44 documentos, datados de 1712 a 1719 , com inventários de navios, instruções secretas, documentos sobre o asiento dos negros, etc. A questão do apresamento de três navios de Buenos Aires pelos Portugueses antes da 
Entretanto, embora a Paz de Utrecht tenha sido baseada no consenso e a diplomacia inglesa demonstrasse saber conduzir as negociações de forma a evitar a criação de desequilíbrios no interior do "sistema europeu de Estados", questões houve que constituíram um foco de problemas, como sucedeu com a Casa de Sabóia, cujo titular recebeu a Sicília, a dignidade de rei e o direito de poder suceder no trono de Espanha. A cláusula não agradou a Filipe V, que, em 1717, decidiu atacar a Sardenha. Apenas a pressão conjunta da França e da Grã-Bretanha terá obrigado o rei de Espanha a desistir do seu intento ${ }^{35}$. Neste quadro, a diplomacia portuguesa foi mobilizada para se saber qual seria a atitude de Espanha face a Portugal. Em ofício datado de 17 de Fevereiro de 1718, o conde de Tarouca, embaixador na Holanda, informava que tivera

uma longa conferencia com o Ministro dos Negócios estrangeiros d'aquella Republica, na qual o dito Ministro lhe segurara que a Hollanda pelo seu interesse desejava a tranquillidade de Portugal, e que fará sempre tudo quanto podér para impedir que a Hespanha declare a guerra a Portugal; que o dito Ministro intende que os Castelhanos farão um grande erro em atacar-nos, e concordou em assentar que os movimentos de Filippe V hão de ser regulados pelo partido francez de Luiz XIV ${ }^{36}$.

A conjuntura balizada pela formação da Quádrupla Aliança, em 1718, que se opunha às ambições de Filipe V -que, em 1720, acabaria por integrar a mesma, renunciando ao trono francês-, e a assinatura do Tratado de Cambrai, a 27 de Março de 1721, confirmando a nova aliança franco-espanhola, revelou-se preocupante para os interesses portugueses na América do Sul ${ }^{37}$. Neste contexto, era essencial garantir o reforço do povoamento português no Brasil meridional com a refundação da Colónia do Sacramento. Em 1716, António Rodrigues Carneiro, que havia servido nove anos como capitão de infantaria, fora nomeado sargento-mor da Colónia do Sacramento ao voluntariar-se para repovoar o território, levando consigo e com sua família trinta casais transmontanos ${ }^{38}$. A coroa cuidou de assegurar que o governador do Rio de Janeiro prestaria todo o apoio aos militares e povoadores, cujo número se fixara nos sessenta casais. Estes partiram do Porto com destino ao Rio de Janeiro na companhia do sargento-mor. No Rio de Janeiro juntaram-se-lhes oficiais e soldados que iam servir na praça e dali embarcaram rumo à Colónia, onde aportaram em co-

publicação da guerra e o pagamento a Portugal de 600.000 pesos esteve em jogo durante as negociações de Utrecht. Dois navios foram confiscados no porto do Rio de Janeiro, onde deram entrada no dia 8 de Setembro de 1703 (fl. 22) e um deu à costa na Quarteira, Algarve, a 7 de Março de 1704 (fl. 15). Nestas datas, afirmavam os ministros espanhóis, "no hauía entonces Guerra entre esta Corona, y la de Portugal, pues se publico en 30 de Abril de 1704" (fl. 22), embora as consequências da declaração de guerra se tenham feito sentir na situação.

35 Cf. BLACK, J.: La Europa del siglo XVIII 1700-1789, Madrid, Akal, 1997, p. 349.

36 Cf. SAntarém, Visconde de: Quadro Elementar das Relações Politicas e Diplomaticas de Portugal com as diversas Potencias do Mundo, desde o principio da Monarchia Portugueza até aos nossos dias, Impresso por ordem do Governo Portuguez, Paris, Em Casa de J. P. Aillaud, Tomo Segundo, 1842, pp. 174-175.

37 Cf. Almeida, A. F.: A formação do espaço brasileiro e o projecto do Novo Atlas da América Portuguesa (1713-1748), Lisboa, Comissão Nacional para as Comemorações dos Descobrimentos Portugueses, 2001, pp. $66-72$.

38 Arquivo Nacional da Torre do Tombo (ANTT), Chancelaria de D. João V, livro 146, fls. 267 v-268. 
meços de $1718^{39}$. Alguns anos depois, mais trinta casais de Trás-os-Montes seguiriam para a Colónia do Sacramento acompanhando o novo governador, António Pedro de Vasconcelos. Foram estes migrantes que estiveram na origem de um período de crescimento económico da Colónia, caracterizado pela expansão da pecuária, a exportação de couros e prata e o contrabando e beneficiando da isenção por dez anos da cobrança de direitos reais sobre os géneros autorizados no comércio com a colónia, concedida por D. João $\mathrm{V}^{40}$.

Porém, a vida dos colonos nessa sociedade de fronteira foi pautada, desde a sua chegada, por várias adversidades. Desde logo, nos primeiros dias de 1719, o governador Manuel Gomes Barbosa escreveu a D. João V comunicando que não tinha sido possível distribuir a cada um dos casais a légua de terras que o rei determinara ${ }^{41}$. A esta situação, somavam-se a pressão castelhana e os ataques dos índios Guarani sob jurisdição das missões do Paraguai. As duras condições que os colonos trasmontanos encontraram estão bem espelhadas na elevada mortalidade infantil. Não é, pois, de admirar que várias pessoas tenham optado por fugir para o lado castelhano.

Perante este cenário e dada a urgência de consolidar a posição portuguesa na bacia do Prata, o rei e o Conselho Ultramarino ofereceram uma recepção muito positiva à súplica das populações da ilha do Pico, assolada por uma crise sísmica e vulcânica nos anos de 1717, 1718 e 1720. Atingidos pelos efeitos da crise, os povos da ilha requeriam passar às "partes do Brazil". Em consulta de 31 de Outubro de 1720, a posição do Conselho Ultramarino acerca da representação dos picoenses foi exposta de forma clara: o requerimento devia ser atendido não apenas por ser obrigação dos reis acudir à necessidade dos seus vassalos e remediar o seu sofrimento, mas, "muito principalmente", quando o "remédio" proposto

he o que maes conuem ao seruisso de vossa magestade e defesa e bom gouerno da monarchia por ser preciso e muito necessario que se pouoe a costa do sul que corre do porto de Santos para sul athe a Noua Colonia, porque contendo esta costa os milhores portos de toda a America portugueza e podendo por esta cauza recear se justamente que os navios da Europa uendo as desemparadas as queirão ocupar, como proximamente o fizerão os francezes com hua armada na boca do rio da Prata ${ }^{42}$.

39 Consulta do Conselho de Estado com despacho de 3 de Agosto de 1717, AHN, Estado, leg. 1773, n. ${ }^{\circ} 5$ [s. $\mathrm{n}^{\circ}$.]. Esta consulta é relativa ao decreto de 23 de Julho de 1717 enviado ao mesmo Conselho de Estado com carta do marquês de Capecelatro de 29 de Junho sobre a entrega da Colónia do Sacramento a Portugal, que refere a ida de sessenta famílias da cidade do Porto para povoamento da Colónia; Annaes da Bibliotheca Nacional do Rio de Janeiro, Rio de Janeiro, vol. XXXIX, 1917, pp. 369-370; MARQues, V. S.: Edição semidiplomática de História Topográfica e Bélica da Nova Colônia do Sacramento do Rio da Prata, códice 677, da Biblioteca Nacional de Lisboa, dissertação de Mestrado apresentada ao Programa de PósGraduação em Filologia e Língua Portuguesa, São Paulo, Faculdade de Filosofia, Letras e Ciências Humanas da Universidade de São Paulo, 2008, policopiado, pp. 153-154.

40 Para referências ao contrabando hispano-português no Rio da Prata, ver Solano, op. cit., (nota 4), pp. 204-205; CÉSPEDES, op. cit., (nota 3), pp. 158, 163 y 291; Ver também MARQues, op. cit., (nota 39), p. 154.

41 Carta de 6 de Janeiro de 1719, Arquivo Histórico Ultramarino (AHU), Conselho Ultramarino (CU), Nova Colónia do Sacramento, caixa 1, doc. 42.

42 AHU, CU, Açores, caixa 2, doc. 30, in Arquivo dos Açores, $2^{\mathrm{a}}$ Série, Ponta Delgada, Universidade dos Açores, vol. II, 2001, doc. 31, pp. 184-186. O original coloca problemas de leitura e a transcrição paleográfica assinalou as dúvidas e as palavras riscadas, referências que eliminámos na citação. 
Para os conselheiros, em nome da segurança e do aumento do Estado do Brasil, era urgente mandar povoar todos os portos até aos rios de São Francisco Xavier e Rio Grande de São Pedro e ainda povoar a ilha de Santa Catarina, cujos moradores, em reduzido número, "uiuem a medo dos piratas, que os obrigão a fornecer lhe os mantimentos e agoada" 43 , palavras que parecem antecipar as que Sebastião da Rocha Pita registará na sua história. O parecer dos conselheiros ia de encontro aos argumentos que eram defendidos pela diplomacia portuguesa e que ficaram plasmados em mapa do $1^{\circ}$ marquês de Abrantes, D. Rodrigo Annes de Sá Almeida e Menezes (16761733), cobrindo o território da Colónia do Sacramento ${ }^{44}$.

A publicação da lei de 20 de Março de 1720, com aplicação nas ilhas, surgiu como um entrave à livre circulação de homens entre o reino e o Brasil ao exigir uma justificação documental a todos os que para aí se pretendiam deslocar. Não obstante, a coroa continuou a apoiar e a promover a saída de casais ilhéus para a América do Sul sempre com o objectivo de povoar e defender as regiões fronteiriças. Assim, entre 1720 e 1723, o Conselho Ultramarino procurou organizar, com a colaboração do corregedor dos Açores e das câmaras locais, o alistamento de casais que deveriam rumar ao Brasil meridional. Estes colonos, na sua maioria em situação de grande pobreza devido à devastação causada pela erupção, recebiam sementes e ferramentas e eram transportadas à custa da coroa para as costas do Brasil, onde esperavam receber "terras iguais às da Europa". A estes, o corregedor dos Açores considerava que podiam somar-se os presos, aumentando-se assim o contingente dos colonos ${ }^{45}$.

$\mathrm{O}$ embaixador de Filipe $\mathrm{V}$ em Lisboa, sempre atento a estas matérias, não deixou de informar o seu soberano sobre o projecto português de enviar famílias das ilhas dos Açores para a Colónia do Sacramento, e o Consejo de Indias foi de novo chamado a pronunciar-se sobre o assunto ${ }^{46}$. A iniciativa portuguesa até adquiriu maior relevo após o episódio da ocupação do sítio de Montevidéu pelos Portugueses, em 1723 -durante a realização do Congresso de Cambrai-, e que terminou em $1725^{47}$. No ano seguinte, chegaram a Montevidéu os primeiros povoadores idos das Canárias, com o apoio de Buenos Aires ${ }^{48}$. Perante esta iniciativa, o governador da Colónia escreveu para o reino, defendendo a criação de novas povoações desde o litoral de Santa Catarina até ao Rio Grande de São Pedro ${ }^{49}$. Ora, estas fundações exigiam o recurso a mais gente. Todavia, face às dificuldades que se experimentavam no financiamento

43 Ibidem, p. 186.

44 Biblioteca Nacional de Portugal (BN), Arquivo Tarouca (AT), 228//1, Negociaçoens do Conde de Tarouca em Vienna de Austria. Instrução, e ordens del Rey, e documentos que se receberão juntamente com a Instrução, (1726), Tomo I, fl. 128.

45 Cf. AHU, CU, Açores, caixa 2, doc. 33, in Arquivo dos Açores, $2^{\mathrm{a}}$ Série, vol. II, 2001, doc. 33, de 22 de Agosto de 1722, pp. 188-189.

46 Cf. Pastells, P. S. J.: Historia de la Compañia de Jesús en la provincia del Paraguay (Argentina, Paraguay, Uruguay, Perú, Bolivia y Brasil) según los documentos originales del Archivo General de Indias, t. 6 (1715-1731), Madrid, Consejo Superior de Investigaciones Científicas, Instituto Santo Toribio de Mogrovejo, 1946, pp. 292-293, 9 de Dezembro de 1723.

47 Cf. Cluny, op. cit., (nota 14), pp. 410-412.

48 Cf. Azarola Gil, L. E.: Los orígenes de Montevideu (1607-1749), Buenos Aires, Librería y Editorial "La Facultad", 1933, pp. 92, 116-117, 125 y 258-261.

49 Cf. "Catálogo de manuscritos sobre o Rio Grande do Sul existentes na Biblioteca Nacional", Anais da Biblioteca Nacional, Rio de Janeiro, 99 (1979), pp. 3-142, p. 9. 
dos custos de transporte e no alistamento dos casais dos Açores, em 1729 a coroa portuguesa suspendeu temporariamente o projecto de transportar mais casais para o Brasil $^{50}$.

3. É muito provável que, no final da década de 1720 , as atenções de D. João V estivessem sobretudo voltadas para o diferendo que mantinha com Roma e para as negociações em torno do duplo enlace dos príncipes de Portugal e Espanha, o que pode também ter contribuído para uma menor dinâmica do processo de alistamento de casais açorianos. Esta foi, aliás, a explicação apresentada por Simão Pereira de Sá, natural do Rio de Janeiro, que argumentou terem sido os "vinculos novos de parentescos" que se teciam de novo entre as duas coroas ibéricas que levaram o monarca português a ceder e a não responder ao envio de população canária para Montevidéu ${ }^{51}$. Com efeito, a "troca das princesas", como em outras semelhantes ocasiões, forneceu o pretexto para toda uma literatura panegírica aclamar ambos os reinos "venturosamente unidos" e proclamar que "agora sim; se augmentaráõ os seus Estados; dilataràõ os seus Dominios; porque uniformes no imperio daõ os braços de concordes, e gozaráõ os Vassallos de hum, e outro Reyno dos doces suaves fruttos de huma eterna aliança". O padre Manuel dos Reis Bernardes, cónego da Sé do Porto, que citamos, reforçou a ideia das consequências positivas da "concordia feliz" afirmando que "já naõ pareceraõ Portugal, e Castella dous Reynos distinctos; mas sim pelo amor dous em hum só Reyno identificados" 52 . Todavia, não obstante a formulação destes votos, alguns dos obstáculos que impediam a maior aproximação entre os dois reinos continuavam a existir, alimentando a desconfiança. E, como referiu John Lynch, haveria "an element of Lusophobia in Spanish thinking" ${ }^{53}$.

Assim, não é de estranhar que em 1735, depois de uma fase de relativo adormecimento, houvesse um reacender das hostilidades em torno do controlo da bacia do Prata. A disputa manteve-se até 1737, período durante o qual a Colónia do Sacramento esteve cercada e sujeita à pressão militar exercida pelo governador Miguel de Salcedo, sucessos que tiveram eco na corte portuguesa e deram ensejo

50 Sobre estas movimentações, ver Arquivo dos Açores, $2^{\text {a }}$ Série, vol. II, 2001, docs. 31-38, pp. 184-223, de 31 de Outubro de 1720 a 12 de Fevereiro de 1723, e docs. 40, 41 e 42, pp. 254-258, de Julho de 1723 a Janeiro de 1724; Meneses, A. F.: Gentes dos Açores: o número e a mobilidade em meados do século XVIII, trabalho elaborado no âmbito da prestação de Provas de Agregação, Ponta Delgada, Universidade dos Açores, 1997, policopiado, e do mesmo autor, "Os Ilhéus na colonização do Brasil: O caso das gentes do Pico na década de 1720”, Arquipélago-história, Ponta Delgada, 2 2 Série, 3 (1999), pp. 251-264; e Rodrigues, J. D.: "Das ilhas ao Atlântico Sul: a política ultramarina e a emigração açoriana para o Brasil no reinado de D. João V", Anais de História de Além-Mar, Lisboa, 8 (2007), pp. 57-68.

51 Marques, op. cit., (nota 39), p. 167.

52 Cf. Bernardes, M. R.: Panegyrico Evangelico, Epithalamico, e Gratulatorio na Solennidade, que na Santa Igreja Cathedral do Porto fez em 5. de Fevereyro de 1728. o Nobilissimo Senado da mesma Cidade em Acçaõ de Graças pelos Augustissimos Despozorios dos Serenissimos Senhor D. Joseph Principe do Brasil, a Senhora D. Marianna Vitoria, Infanta de Castella; e dos Serenissimos Senhor D. Fernando Principe das Asturias, e Senhora Dona Maria Barbara Infanta Primogenita de Portugal, [...]., Lisboa Ocidental, Na Patriarcal Oficina da Música, 1728, pp. 1, 8-9 e 18 para as citações.

53 LyNCH, op. cit., (nota 6), p. 132. 
a notícias contraditórias ${ }^{54}$. A Convenção de Paris de 15 de Março de 1737 permitiu declarar o fim das hostilidades na América do Sul, embora, no mesmo ano, Portugal reforçasse a sua presença na região sul do Brasil contra a oposição espanhola, com a formação de um regimento de dragões na Nova Colónia ${ }^{55}$ e a fundação do presídio do Rio Grande pelo brigadeiro e engenheiro-militar José da Silva Pais, responsável pelas obras de defesa do Rio de Janeiro ao Rio da Prata. A nomeação de José da Silva Pais- tal como, uns anos antes, a de Gomes Freire de Andrade -inscreve-se no contexto da inflexão que Maria Fernanda Bicalho registou na política imperial joanina, sublinhando, na esteira de Jaime Cortesão, que a década de 1730 foi caracterizada pelo "envio de um novo perfil de governadores e ministros para o ultramar" ${ }^{56}$. Foi o mesmo José da Silva Pais quem assegurou a defesa da ilha de Santa Catarina, quando esta, juntamente com o Rio Grande, foi separada da capitania de São Paulo, ficando os dois territórios na dependência jurisdicional da capitania do Rio de Janeiro ${ }^{57}$. E coube ao engenheiro-militar demonstrar a real importância geoestratégica da ilha de Santa Catarina, afirmando, de forma categórica, em 1737: "Eu sou o primeiro que reconheço que é preciso que na Ilha de Santa Catarina haja alguma fortificação e quem a governe, e isso mesmo mandei dizer a Santos, pois sem dúvida nos seria muito sensível perdê-la" 58 .

Em 1738, foi criada a capitania de Santa Catarina, na dependência da do Rio de Janeiro, e José da Silva Pais nomeado para o seu governo. Visitou a região e constatou que o povoamento era débil, colocando, por isso, problemas no tocante à defesa da ilha de Santa Catarina e do litoral. Deste modo, em 1742, o governador escreveu a D. João V, defendendo que a presença de casais das ilhas em Santa Catarina era necessária para a conservação do espaço geoestratégico sul-brasileiro. Também o Conselho Ultramarino, onde tinham assento ministros conhecedores dos negócios do Brasil, como o desembargador Rafael Pires Pardinho ou Alexandre de Gusmão, se pronunciou a favor do recrutamento de famílias das ilhas em consulta de 30 de Março de 1745, considerando que aquelas eram precisas para a defesa e povoamento do Brasil.

54 Cf. Lisboa, J. L., Miranda, T. C. P. R., Olival, F.: Gazetas manuscritas da Biblioteca Pública de Évora, vol. 3 (1735-1737), Lisboa, Edições Colibri-CIDEHUS-CHC, 2011, pp. 159, 176-177, 192, 228-230, 233, 237, 239-241, 243-244, 246, 248, 251 y 292 para referências a estes eventos até ao fim do conflito; BÉTHENCOURT Masieu, A.: Relaciones de España bajo Felipe V. Del Tratado de Sevilla a la Guerra con Inglaterra (17291739), Valladolid-La Laguna-Las Palmas, Universidad de Valladolid-Universidad de La Laguna-Universidad de Las Palmas, 1998, pp. 377-398; CoRTesão, op. cit., (nota 8), t. 2, pp. 59-81; AlmeIDA, op. cit., (nota 8), pp. $17-25$.

55 LisBoA, op. cit., (nota 54), p. 253, 4 de Junho de 1737.

56 Cf. Bicalho, M. F.: "Inflexões na política imperial no reinado de D. João V”, Anais de História de AlémMar, Lisboa, 8 (2007), pp. 37-56, p. 54 para a citação e p. 55, nota 64.

57 Cf. ReIs, A. C. F.: "Pais, José da Silva (século XVIII)", en Serrão, J. (dir.): Dicionário de História de Portugal, v. 4, Porto, Livraria Figueirinhas, 1981, pp. 516-517; MARTINIĖRE, G.: "A implantação das estruturas de Portugal na América (1620-1750)", en Mauro, F. (coord.): O Império Luso-Brasileiro (1620-1750), Nova História da Expansão Portuguesa, direcção de Joel Serrão e A. H. de Oliveira Marques, Lisboa, Editorial Estampa, vol. 7, 1991, pp. 91-169, maxime pp. 162-163; SILVA, op. cit., (nota 19), p. 213.

58 Cf. SAlomon, M.: "O exílio da desordem e a segurança da Ilha de Santa Catarina no século XVIII", en Brancher, A., Arend, S. M. F. (orgs.): História de Santa Catarina: séculos XVI a XIX, Florianópolis, Editora da UFSC, 2004, pp. 79-92, 88-89 para a citação. 
A monarquia espanhola, envolvida no conflito conhecido como Guerra da Orelha de Jenkins, iniciada em 1739 e que se confundiu com a Guerra de Sucessão da Áustria (1740-1748), não tivera a janela de oportunidade para incrementar uma resposta adequada às iniciativas portuguesas. Portugal, escudando-se nos tratados de 1703, optara por manter uma posição neutral, o que permitiu a D. João $V$ evitar o desvio de meios humanos e materiais para um conflito que não lhe interessava. A opção pela paz do soberano português e dos seus mais próximos conselheiros foi, de resto, elogiada por D. Luís da Cunha no seu Testamento Político (ou Carta de conselhos ao Príncipe D. José), texto cuja redacção terá começado em 1742, após D. João V ter sido acometido, em Maio desse mesmo ano, de um ataque que o paralisou e privou de sentidos, ficando o monarca hemiplégico e parcialmente incapacitado. Colocou-se, por esse motivo, a questão do eventual afastamento do rei da acção governativa e a entrada em cena do seu sucessor, situação que levou o experiente diplomata a pegar na pena e a escrever os seus conselhos para o príncipe ${ }^{59}$.

$\mathrm{O}$ soberano português sobreviveu à doença, ainda que limitado. Quando, em 1746, faleceu o espelho ibérico de D. João V, Filipe V, a subida ao trono de Fernando VI, casado com D. Bárbara de Bragança, princesa do Brasil, constituiu um momento de viragem nas relações diplomáticas luso-espanholas. Se a atenção do novo rei e dos seus ministros estava orientada para o cenário europeu, por um lado, e a guerra contra a potência naval britânica, por outro ${ }^{60}$, já a acção da rainha de Espanha, encabeçando o "partido português", aliado na corte espanhola do "partido fernandino" 61 , e contando com a colaboração do ministro José de Carvajal, de ascendência portuguesa (Casa de Aveiro), contribuiu para o estreitamento das relações entre Portugal e Espanha, abrindo caminho para novas negociações entre as coroas ibéricas e para a assinatura do Tratado de Madrid, em 1750.

À data do começo das negociações, Portugal possuía já mapas muito mais correctos e detalhados da América do Sul. Era uma consequência do investimento de D. João V na produção cartográfica, como advogara $\mathrm{D}$. Luís da Cunha, que se empenhara em conseguir a colaboração de geógrafos franceses, nomeadamente a de Jean-Baptiste Bourguignon D'Anville, para desenvolver a arte da cartografia em Portugal ${ }^{62}$. E neste contexto que podemos inscrever a missão dos chamados Padres Matemáticos no Brasil, com vista à elaboração do Novo Atlas da América Portuguesa, peça essencial para um melhor conhecimento do território sul-americano, com reflexos na administração e na fiscalidade, e sobretudo para a defesa da soberania portuguesa sobre os territórios disputados pela França e por Espanha. A missão, que decorreu entre os anos de 1730 e 1748, traduziu-se na produção de cerca de vinte mapas, oito plantas

59 Cf. Silva, A. D.: Testamento Político de D. Luís da Cunha, Lisboa, Biblioteca Nacional de Portugal, 2013, pp. 23-24, 87 y 97.

60 Para as complexas relações diplomáticas e comerciais entre Espanha e Inglaterra nessa época, ver García Fernández, M. N.: Comerciando com el enemigo: El Tráfico Mercantil Anglo-Español en el Siglo XVIII (1700-1765), Madrid, CSIC, 2006 e, numa outra perspectiva; RIVAs IBÁÑEz, I.: Mobilizing Resources for War: the British and Spanish Intelligence Systems during the War of Jenkins 'Ear (1739-1744), PhD in History, Londres, University College London, 2008.

61 Cf. Lynch, op. cit., (nota 6), p. 92; MarchenA, op. cit., (nota 4), pp. 62-64.

62 Cf. Furtado, J. F.: Oráculos da Geografia Iluminista. Dom Luís da Cunha e Jean-Baptiste Bourguignon D'Anville na construção da cartografia do Brasil, Belo Horizonte, Editora UFMG, 2012. 
dos fortes do Rio de Janeiro e uma planta da colónia do Sacramento. O projecto ficou incompleto. Contudo, os resultados alcançados foram da maior importância para preparar as negociações do Tratado de Madrid, para as quais Espanha contou com os resultados da expedição de Jorge Juan e Antonio de Ulloa ${ }^{63}$. É preciso lembrar que Jorge Juan, de resto, afirmara de forma muito clara que, no que respeitava à delimitação dos territórios sul-americanos das monarquias ibéricas, "reconociendo al Meridiano de Demarcacion como legitima barrera de las conquistas de cada una", ao referir-se ao Tratado de Utrecht, afirmou sem hesitar que a Nova Colónia do Sacramento "fue en su origen un establecimiento ilegitimo, y furtivo", que, por esse motivo, nunca teve mais território do que "el indispensable del alcance del cañon" ${ }^{64}$. No entanto, o mesmo navegador terminou a sua dissertação, declarando que esperava que os equívocos, erros ou ignorância sobre essa matéria fossem afastados, permitindo um acordo que colocasse os limites da demarcação dentro do que fora concedido pela Santa Sé e que fosse conforme à razão e à justiça, permitindo manter os vínculos de amizade e parentesco entre os príncipes espanhol e português ${ }^{65}$.

Era este o cenário internacional do final do reinado de D. João $\mathrm{V}$ e foi neste contexto que se iniciou o fluxo migratório que uniu os Açores à América portuguesa. Em 1746, a morte de Filipe V e a mudança no horizonte bourbónico de D. João V permitiram reunir as condições que, por fim, possibilitaram o alistamento e transporte de casais para as partes meridionais do Brasil. Nesse mesmo ano, os moradores dos Açores pediram ao rei que os autorizasse a passar aos sertões que se achavam desertos, articulando os argumentos da existência nas ilhas de uma "grande multidão de povo que nelas se acha sem emprego nem meios para subsistir e a necessidade que ha de povoadores para o Brasil" ${ }^{\prime 6}$. Para as populações de mais parcos recursos, a emigração surgia como uma forma de fuga às crises cerealíferas e à fome; para a coroa, que tratava de negociar com a Espanha os limites entre os territórios sul-americanos de ambas as monarquias, o requerimento dos açorianos revelava-se de grande utilidade, respondendo aos objectivos estratégicos perseguidos.

O Conselho Ultramarino pronunciou-se favoravelmente quanto à proposta, em consulta datada de 8 de Agosto de 1746, sublinhando os conselheiros a utilidade e importância do transporte dos casais em matéria de defesa e de finanças; propondo o recurso a empréstimos para garantir a deslocação de 4.000 casais, à razão de 50.000 réis por unidade familiar; e sugerindo a publicação de editais nas ilhas, que poderiam ir acompanhadas por uma recomendação da Secretaria de Estado da Marinha e do

63 Cf. Ramos Gómez, L.: "Jorge Juan y Antonio de Ulloa y el Meridiano de Tordesillas: La Disertacion Historica y Geografica (1747-1776)", en Bravo Guerreira, C., Martínez de Codes, R., M. y otros: El Tratado de Tordesillas y su época, t. 3, Madrid, Sociedad V Centenario del Tratado de Tordesillas-Comissão Nacional para as Comemorações dos Descobrimentos Portugueses, 1995, pp. 1561-1592; VALVERde Pérez, N.: Un mundo en equilibrio. Jorge Juan (1713-1773), Madrid, Marcial Pons, 2012; ALMEIDA, op. cit., (nota 37).

64 Juan, J. (D.): Dissertacion Historica, y Geographica sobre el Meridiano de Demarcacion entre los Dominios de España, y Portugal, y los parages por donde passa en la America Meridional, conforme à los Tratados, y derechos de cada Estado, y las mas seguras, y modernas observaciones: Por [...], En Madrid, en la Imprenta de Antonio Marin, 1749, pp. 7 y 93.

65 Ibidem, pp. 172-173.

66 AHU, CU, Açores, caixa 3, doc. 10, de 1 a 8 de Agosto de 1746, in Arquivo dos Açores, $2^{\text {a }}$ Série, vol. III, 2005, doc. 10, pp. 23-34, maxime p. 23 para a citação. 
Ultramar no sentido de se executarem as ordens do Conselho Ultramarino, apesar de os Açores não estarem sob a jurisdição deste órgão. Em 1746 e 1747, foram emitidas ordens para o corregedor dos Açores contendo as disposições que deviam ser seguidas no alistamento dos casais; o regimento que organizava o transporte foi distribuído pelas autoridades; e o Conselho Ultramarino elaborou um "lembrete" relativo ao modo como os casais deviam instalar-se, procurando coordenar a actuação entre os ministros régios nas ilhas e no Brasil. $\mathrm{O}$ transporte foi arrematado a diversos homens de negócio, com destaque para Feliciano Velho de Oldenberg. O primeiro contingente de casais partiu dos Açores em Outubro de 1747, aportando em território brasileiro no início de Janeiro do ano seguinte ${ }^{67}$.

Convirá acrescentar que, paralelamente a esta migração patrocinada pela coroa portuguesa, continuava a verificar-se a circulação de indivíduos unindo as várias partes do Atlântico português e, em concreto, os Açores ao Brasil. Na maior parte dos casos, tratava-se de gente de escassos recursos, que encontrava na migração uma fuga à miséria. As vastas terras do Brasil surgiam como um espaço de oportunidade. Uns buscaram apoio em redes familiares pré-existentes, tentando a sorte no trato mercantil; outros, entrando pelo porto do Rio de Janeiro, acabavam alistados e seguiam rumo à Colónia do Sacramento. Entre estes estavam, por exemplo, os dois filhos de Bárbara Pereira de Sousa, mulher viúva, natural e moradora na ilha de São Jorge, que partiram "para os estados do Brazil a tratar de suas vidas para ampararem a sua may veuva". Na América portuguesa, assentaram praça em 1743. Após cinco anos de serviço, receberam a notícia de que sua mãe, só e desamparada, requerera ao rei pelo Conselho Ultramarino que fosse autorizado o regresso dos filhos a casa como meio de sobrevivência ${ }^{68}$.

O fluxo migratório iniciado em 1747 foi um movimento controlado pela monarquia portuguesa, que regulamentou a saída dos colonos ilhéus e disciplinou a sua fixação em território sul-americano, quer na Amazónia -Pará e Maranhão-, quer sobretudo na região dos actuais Estados de Santa Catarina e do Rio Grande do Sul. No que respeita ao estado e à condição social dos colonos, partiram essencialmente casais, mas também indivíduos solteiros de ambos os sexos, de humildes recursos, pobres ou no limiar da pobreza, entre os quais encontramos lavradores, cavadores, trabalhadores e oficiais mecânicos. $\mathrm{O}$ total exacto de indivíduos não recolhe a unanimidade dos autores que se dedicaram a estudar este fluxo migratório. Em 1747, entre casais e solteiros, estavam alistadas cerca de 8.000 pessoas de várias ilhas; cerca de uma década mais tarde, em 1756, de acordo com um mapa das freguesias de Santa Catarina, os casais das ilhas que ali residiam eram 1.084, num total de 3.421 pessoas $^{69}$.

67 Sobre este processo, ver PiazzA, W. F.: A epopéia açórico-madeirense, 1748-1756, 2ª ed., revista, Funchal, Centro de Estudos de História do Atlântico, Secretaria Regional do Turismo e Cultura, 1999; Meneses, op. cit., (nota 50); Rodrigues, op. cit., (nota 50).

68 Requerimento anterior a 17 de Outubro de 1749, AHU, CU, Açores, caixa 3, doc. 39, in Arquivo dos Açores, $2^{\text {a }}$ Série, vol. III, 2005, doc. 42, pp. 140-146.

69 Sobre as cifras deste fluxo migratório, ver BolÉo, M. P.: Filologia e História. A emigração açoriana para o Brasil (Com documentos inéditos), Coimbra, Edição da Casa do Castelo, Editora, 1945, p. 8; CABRAL, O. R.: "Os Açorianos", en Anais do Primeiro Congresso de História Catarinense, vol. 2, Florianópolis, Imprensa Oficial, 1950, pp. 503-608, com documentos; PiAzZA, op. cit., (nota 67); PiAzZA, W. F., FARIAs, V. F.: "O contributo açoriano ao povoamento do Brasil", en Actas da III Semana de Estudos da Cultura Açoriana e 
Conhecemos a distribuição por ilhas dos indivíduos de ambos os sexos alistados em 1747 no seguimento da carta régia de 5 de Setembro de 1746. Os elementos reproduzidos no Quadro 1 demonstram que, se exceptuarmos os casos de São Miguel e da Terceira, as demais ilhas cujos habitantes participaram no movimento migratório contribuíram com colonos em percentagens significativas, especialmente São Jorge. Deste modo, não é de estranhar que, em quatro ilhas (Graciosa, São Jorge, Pico e Faial), a emigração de inúmeros casais para o Brasil entre 1748 e 1756 se tenha reflectido negativamente na respectiva evolução populacional. Refiramos, por fim, que a migração de meados de Setecentos não se destinou exclusivamente a Santa Catarina, mas também ao Pará e Maranhão ${ }^{70}$.

QUADRO $1^{71}$

DISTRIBUIÇÃO POR ILHAS DOS ALISTADOS PARA O BRASIL (1747)

\begin{tabular}{|c||c|c|c|}
\hline ILHAS & HABITANTES & ALISTADOS & $\%$ \\
\hline São Miguel & 54.670 & 328 & 0,60 \\
\hline Terceira & 26.433 & 919 & 3,48 \\
\hline Graciosa & 8.037 & 771 & 9,59 \\
\hline São Jorge & 13.995 & 2.820 & 20,15 \\
\hline Pico & 20.639 & 1.816 & 8,80 \\
\hline Faial & 16.669 & 1.287 & 7,72 \\
\hline AÇORES & 151.573 & 7.941 & 5,24 \\
\hline
\end{tabular}

4. O surto migratório que teve lugar nos anos de 1747 a 1756 condicionou a evolução demográfica de algumas ilhas açorianas nas décadas de 1760 e 1770, mas não é menos verdade que contribuiu, de forma decisiva, para o povoamento do litoral sul-brasileiro e a defesa das pretensões portuguesas num espaço de reconhecida importância geoestratégica para as monarquias ibéricas e sobre o qual os interesses portugueses se continuariam a manifestar até ao século XIX ${ }^{72}$. De facto, tal como o Tratado de Utrecht não encerrou a disputa ibérica pelo controlo da bacia do Prata, também o Tratado de Madrid não se constituiu como o culminar de complexos pro-

Catarinense, Ponta Delgada, 30 Outubro-4 Novembro 1989, Ponta Delgada, Universidade dos Açores, 1993, pp. 191-220, com dados demográficos; MAdeIRA, A. B.: População e emigração nos Açores - 1766-1820, Cascais, Patrimonia, 1999.

70 Cf. Madeira, op. cit., (nota 69), pp. 272-274; Meneses, op. cit., (nota 50), p. 102.

71 Fonte do Quadro 1: MADEIRA, op. cit., (nota 69), p. 209, Quadro 93.

72 Cf. TeJERINA, M.: "Frontera e inmigración en épocas de revolución: la situación de los portugueses en el Río de la Plata", Nuevo Mundo Mundos Nuevos [on line], Debates, 2009, colocado on line a 27 de Março de 2009 [URL: <http://nuevomundo.revues.org/index53842.html>]. 
cessos negociais que envolviam diplomacia, guerra e trato mercantil e que, em parte, se entrecruzaram com a complexa "questão jesuítica" que marcou os reinados de D. José I, em Portugal, e de Fernando VI e Carlos III, em Espanha. Novos conflitos entre as duas monarquias eclodiram e outros tratados $(1761,1777,1778)$ foram firmados, procurando fixar fronteiras e definir com precisão as áreas de soberania de Portugal e Espanha na América do Sul com recurso a equipas de demarcação e expedições científicas $^{73}$. Aqueles tratados, como, de resto, os anteriores, não decorriam unicamente do equilíbrio político e militar existente num dado momento entre as monarquias ibéricas. Com efeito, as relações diplomáticas que se teciam entre as coroas portuguesa e espanhola tinham como pano de fundo o "balance of power" consagrado em Utrecht, o iustum potentiae aequilibrium ${ }^{74}$.

É certo que o conceito de "equilíbrio de poder" estava estreitamente associado ao problema da segurança, quer se tratasse da segurança da Europa, quer da de cada uma das formações políticas que a compunham, fossem grandes ou pequenas ${ }^{75}$. Todavia, no contexto geopolítico que se desenhara entre 1713 e 1715, pesavam sobretudo os interesses das principais potências, em concreto a França e a Grã-Bretanha, que disputariam directamente a preponderância até Waterloo ${ }^{76}$. Deste modo, no quadro das relações bilaterais ibéricas, os resultados obtidos ao longo de Setecentos pela prática política e pelas iniciativas diplomáticas de Bourbons e Braganças foram simultaneamente fruto da procura de um equilíbrio entre as duas monarquias e das "diplomacias possíveis" "77 que Espanha e Portugal podiam conduzir, buscando preservar os seus impérios ultramarinos, cada vez mais objecto da cobiça alheia, mesmo por parte dos tradicionais aliados.

73 Cf. Rojo García, M. L.: "La Línea Requena: Fijación científica de la frontera brasileña con Venezuela, Nueva Granada y Perú (1777-1804)", Anexos de Revista de Indias, 4: Estudios (Nuevos e Viejos) sobre la Frontera, coordenados por Francisco de Solano e Salvador Bernabeu, Madrid, 1991, pp. 217-247, e LucENA GiRALDO, M.: "La expedición imaginaria: la ejecución del Tratado de San Ildefonso en la Guayana española (1776-1784)"; Ibidem, pp. 249-276; MARChenA, op. cit., (nota 4), pp. 68-80; FerreirA, M. C.: “A disputa ibérica pelo domínio do Rio Paraguai na segunda metade do século XVIII e a sua representação cartográfica", Navigator. Subsídios para a História Marítima do Brasil, vol. 7, 14: Dossiê Engenharia militar, guerra e representações cartográficas nas Américas dos séculos XVI a XIX, 2011 [<URL: http://www.revistanavigator. com.br/navig14/dossie/N14_dossie5.html] (originalmente reproduzido nos Anais do I Simpósio Brasileiro de Cartografia Histórica, $1^{\circ}$ Simpósio Brasileiro de Cartografia Histórica, Paraty, 10 a 13 de Maio de 2011).

74 Cf. Osiander, op. cit., (nota 10), pp. 138-139.

75 Cf. Bély, L.: L'art de la paix en Europe. Naissance de la diplomatie moderne, XVI ${ }^{e}$-XVIII ${ }^{e}$ siècle, Paris, PUF, 2007, p. 472.

76 Cf. Droz, J.: Histoire Diplomatique de 1648 à 1919, $3^{\text {a }}$ ed., Paris, Dalloz, 1972 (edição original 1952), pp. 68-69 e sobretudo Butel, P.: Histoire de l'Atlantique de l'Antiquité à nos jours, Paris, Perrin, 1997, p. 143.

77 Cf. Molina Cortón, J.: "Carvajal y Floridablanca. Paz, equilibrio y reformismo entre las "diplomacias posibles” del siglo XVIII español”, en Guimerá, op. cit., (nota 11), pp. 207-224. 